\author{
Katarzyna Anna DUDA \\ Uniwersytet Jagielloński \\ k.duda@op.pl
}

\title{
PRZESTRZEŃ FIZYCZNA I BARIERY \\ MENTALNE W DOŚWIADCZENIU \\ EMIGRANTÓW ROSYJSKICH \\ (GRZYBOWSTAPIENIE ZINOWIJA ZINIKA)
}

ABSTRACT Physical Space and Mental Barriers in Russian Emigrants' Experience (The Mushroom Picker by Zinovyi Zynyck)

Taking into account the novel The Mushroom Picker there are a lot of kinds of the word "frontier". Their meaning depends on a question: what we would like to express using them. Not only does the Russian author write about space borders between countries but he considers mental barriers as well. In his opinion, the latter ones are drastically more dangerous because they often lead to arguments and even wars between nations which have no knowledge and understanding of different cultures. The main character of the novel shows the reader both Soviet and English reality. The capital cities of these countries - Moscow and London - are presented critically. The citizens of both countries do not trust each other, and do not even try to know anything about different conditions in which they live. The protagonists are proud only of their own culture and history, and do not respect other nations. There are not any spiritual values, friendship and agreement among people. In this way The Mushroom Picker turned to be very pessimistic.

Key words: Russian emigration, mental differences, overcoming barriers, dehumanization

Słowa kluczowe: emigracja rosyjska, różnica w mentalności, pokonywanie barier, dehumanizacja 
elem niniejszego tekstu jest prezentacja sytuacji, w jakiej znaleźli się rosyjscy
uchodźcy tzw. trzeciej fali emigracji rosyjskiej (koniec lat 60., lata 70. i początek lat $80 . \mathrm{XX}$ w.), którym za samowolne przekroczenie granic państwa radzieckiego groziły surowe represje, włączając osadzenie w łagrze bądź nawet karę śmierci. Drugim problemem wziętym pod uwagę przez Zinowija Zinika w jego powieści Grzybowstapienie (1994) jest wskazanie na trudności w pokonywaniu różnic mentalnych pomiędzy ludźmi wychowanymi na obszarze ZSRR a przedstawicielami Zachodu. Zinik, podobnie jak inni rosyjscy pisarze emigracyjni (Siergiej Dowłatow, Władimir Maksimow, Aleksander Sołżenicyn), akcentuje fakt, iż samo opuszczenie państwa totalitarnego nie jest gwarantem wolności wewnętrznej. Emigracji z ZSRR, z której nie można było powrócić aż do czasów Gorbaczowowskiej pierestrojki, towarzyszyć musiała więc konieczność przystosowania się do otoczenia kraju przyjmującego, ale bez zagubienia własnej tożsamości, związanej z różnorodnymi nawykami, obyczajami, mechanizmami zachowań itp., wypływającymi z rodzimej tradycji. Zinik przedstawia te zmagania z rzeczywistością emigracyjną w krzywym zwierciadle, posługując się ostrzem satyry, przy czym wykreowany przez niego bohater jest konstruktem stricte literackim, a nie (jak to było na przykład w przypadku Dowłatowa) odpowiednikiem twórcy. Zinik, znalazłszy się w Londynie, chętnie i szybko nauczył się języka angielskiego, dzięki czemu otrzymał dobrze płatną posadę, nigdy również nie marzył (inaczej niż bohater jego książki - Kostia) o powrocie do ZSRR, nie wyolbrzymiał znaczenia tego ostatniego na arenie międzynarodowej, współpracował za to z angielskimi kolegami po piórze, zapoznając się gorliwie (odmiennie niż bohater powieści) z różnorodnością obyczajową i mentalną Anglików.

Wypowiadając się na temat granic, czy to rzeczywistych, czy wyobrażonych, warto najpierw zadać pytanie, czym one są. Udzielenie odpowiedzi, wbrew pozorom, nie jest łatwe. Najprostsza definicja dotyczy granic przestrzennych, fizycznych, określających linie zakreślające obszar danego państwa, do którego przyjazd (dobrowolny lub wymuszony) wymaga respektowania jego praw, obyczajów, a więc szeroko pojętej kultury. Powyższe określenie, dotyczące (umownie rzecz ujmując) rozgraniczeń geopolitycznych, połaci ziemi odgrodzonych szlabanami i wieżyczkami pograniczników, ma w tym wywodzie szczególne znaczenie. Odnosi się, z jednej strony, do ekspansjonistycznej metody powstania państwa ruskiego i nasilania się jej wytycznych w czasach radzieckich, kiedy często dzielono świat na krąg pierwszy (najważniejszy) - reprezentowany przez Kraj Rad, krąg drugi, w którego obrębie znajdowały się bratnie kraje socjalistyczne, oraz krąg trzeci - wrogie państwa kapitalistyczne ${ }^{1}$. Z drugiej strony, Związek Radziecki ukazywano niejednokrotnie jako oblężoną twierdzę, do której trudno jest się dostać (tu pojmuje się ZSRR jako ziemski raj, do którego nie mogą przeniknąć żadne wirusy z zewnątrz) i skąd trudno wyjechać. Ten drugi czynnik (trudność wyjazdu) wiąże się m.in. z podejmowanym w utworze Zinika tematem doświadczenia emigracyjnego. Mocno zaciągnięta żelazna kurtyna uczyniła ZSRR przestrzenią szczelnie zamkniętą.

M. Heller, A. Niekricz, Utopia u wtadzy. Historia Związku Sowieckiego, t. 2, przeł. A. Mietkowski, Wrocław 1989, s. 184. 
Wiadomości z Kraju Rad rzadko przedostawały się na zewnątrz, ale równie sporadycznie docierały tam wieści ze świata. Dlatego Rosjanie pozbawieni byli informacji o najnowszych trendach w kulturze, sztuce, a także możliwości głośnego wypowiadania własnego zdania i samodzielnego podejmowania decyzji. Emigrant, opuszczając kraj urodzenia, pozostawał więc (a odnosi się to do przypadku Kostii) istotą nazwaną ironicznie homo sovieticus, obarczoną arsenałem cech negatywnych, takich na przykład jak nieufność, nieumiejętność dokonywania wyboru, podejrzliwość, brak inicjatywy.

Wraz z wprowadzeniem pojęcia homo sovieticus pojawia się konieczność dookreślenia różnic w mentalności ludzi różnych narodowości i różnego pochodzenia. Problematyka powieści Zinika osnuta jest bowiem właśnie wokół różnic mentalnych Rosjanina i Angielki, reprezentantów innych światów, innych sposobów myślenia $\mathrm{i}$ inaczej skonstruowanej hierarchii wartości. Kostia to jeden z całej rzeszy mieszkańców „pierwszego w dziejach” państwa robotników i chłopów budowanego na podstawie moralności kolektywistycznej. Cleo natomiast to typowa obywatelka kraju konserwatywnego, mającego (w odróżnieniu od ZSRR) pielęgnować tradycję i strzec swych korzeni.

$\mathrm{Na}$ emigracji jednak Kostia nie osiąga dobrostanu - ani materialnego, ani duchowego, jego emocje ulegają spotęgowaniu, gdyż każde „niewygodne” pytanie, każdą wypowiedź skierowaną do niego odbiera jako agresję, jako siłowe wtargnięcie w wewnętrzny układ wartości. Sam Kostia uważa, że podlega stałej kontroli, presji wywieranej przez mieszkańców Albionu. Jego wolność wewnętrzna zdaje się stale zagrożona. Trudno jest „herosowi z bylin”, czyli tradycyjnych rosyjskich pieśni epoki średniowiecza, opiewających niezwykłe czyny odważnych bohaterów, pokonać jakiekolwiek trudności i ograniczenia, gdyż w swą mentalność ma wdrukowany skrypt nieumiejętności samodzielnego radzenia sobie z problemami. Tym samym w Anglii Kostia przeistacza się z baśniowego Iwana głuptaska w infantylną istotę wywodzącą swój rodowód właśnie od radzieckiego homososa ${ }^{2}$. Nie respektuje on granic innych, gdyż nie ma świadomości własnych, a więc tego, kim jest, czym dysponuje i za co bierze odpowiedzialność. Kosta nie umie (albowiem wychowany został metodą treningu, tresury ${ }^{3}$ ) sprecyzować własnych pragnień i myli je z potrzebami innych, pozostając niewrażliwym na odrębność, niepowtarzalność drugich jednostek. Bohater Zinika, sam nie zdając sobie z tego sprawy, staje się swego rodzaju napastnikiem, buduje mury powodujące całkowitą izolację od świata osób, brak intymności w kontaktach z ludźmi, a w konsekwencji - samotność. Nie rozumie, gdyż nie miał ani wzorców, ani autorytetów, na których mógłby się oprzeć i pojąć, że każdy człowiek ma prawo do odrębności i własnego rozwoju.

Wszystkie wskazane powyżej cechy mentalności Kostii - człowieka radzieckiego znajdują swoje odzwierciedlenie w powieści zatytułowanej Grzybowstapienie, napisanej przez rosyjskiego emigranta Zinowija Zinika - przedstawiciela trzeciej fali emigracji

Takiego określenia (synonimicznego z homo sovieticusem) użył po raz pierwszy Aleksander Zinowiew. Podaję za: L. Suchanek, Homo sovieticus. Świetlana przysztość. Gnijący Zachód. Pisarstwo Aleksandra Zinowiewa, Kraków 1999, s. 133-157.

3 M. Heller, Maszyna iśrubki. Jak hartowat się cztowiek radziecki, Warszawa 1989, s. 201. 
rosyjskiej, za której początek uważa się rok 19664', a której koniec, jak już wspomniano, przypada na lata pierestrojki. Zainteresowanie badaczy uchodźctwa rosyjskiego skierowane było przede wszystkim ku najbardziej znanym ośrodkom emigracyjnym, takim jak Francja, Niemcy, Stany Zjednoczone. Mniejsza uwaga koncentrowała się na Anglii. Stąd wynika zapewne fakt, że właściwie aż do połowy lat 90 . XX w. niewiele wiedziano o postaci i dorobku twórczym osiadłego w Londynie Zinika. A przecież jest on autorem wielu interesujących powieści i zbiorów opowiadań, wśród których najważniejsze to: Powiadomienie, Osoba deportowana, Nisza w Panteonie, Uchylanie się od obowiazków, Rosyjska rozgtośnia oraz będące przedmiotem tego artykułu Grzybowstąienie. Od połowy lat 80. (wyjechał do Anglii w 1975 r. na fali emigracji żydowskiej) Zinik pisze także utwory w języku angielskim, na przykład The Thieves of History, Mind the Doors, One Way Ticket, Stories... 5 .

Posiadający obywatelstwo brytyjskie Zinik wpisuje się więc w poczet rosyjskich emigrantów-asymilantów: inaczej niż główny bohater Grzybowstąpienia zasymilował się on z nową ojczyzną, zaakceptował jej kulturę, zwyczaje i obyczaje, dobrze włada językiem kraju przyjmującego. A pamiętać należy, co unaocznił Zinik w swej powieści, że język jest jednym z podstawowych wyróżników kultury. Biegłe posługiwanie się językiem obcym ubogaca ludzi, nie odbierając im nic z własnej tożsamości narodowej. Natomiast niechęć do nauczenia się języka państwa, w którym przebywa się przez dłuższy okres, prowadzi nieuchronnie do nieporozumień, konfliktów, a nawet - jak to ma miejsce w Grzybowstąpieniu - do tragedii bohatera. Nieumiejętność prawidłowego korzystania z języka zagranicy sprawia, że człowiek przestaje być istotą dialogiczną, słyszy, ale nie słucha: same wszak dźwięki (jeśli oczywiście pominie się fakt kontekstu i konsytuacji) nie są obciążone semantycznie, nie budują prawdziwego spotkania rozumianego jako koegzystencja z drugim człowiekiem, konstruktywna wymiana myśli i poglądów. Zamiast skracać dystans i budować mosty między narodami, użytkownicy tylko jednego, własnego języka tworzą nieraz barierę/granicę trudną do pokonania. W Związku Radzieckim w programach nauczania była tylko jedna godzina języka obcego ${ }^{6}$, co miało oczywiście podłoże ideologiczne: uniemożliwienie obywatelom zdobywania i korzystania z informacji napływających spoza żelaznej kurtyny. Ponadto ogromny szum informacyjny, trudność w porozumiewaniu i wzajemnym rozumieniu się wprowadziła nowomowa, nagminnie stosowana przez władze i wypełniająca funkcję manipulacyjną - drewniany język, którego głównymi wyróżnikami były wyraźne narzucanie znaku wartości, pragmatyzm-rytualizm oraz magicznośc 7 .

Anglicy, mimo braku takich ograniczeń, mając wybór, również nie uczą się rosyjskiego, skupiając się na zarabianiu pieniędzy, wychwalaniu własnej tradycji i wygłaszaniu

L. Suchanek, „Literatura rosyjska jest tam, gdzie znajduja siępisarze rosyjscy”, [w:] Emigracja i samizdat. Szkice o wspótczesnej prozie rosyjskiej, red. L. Suchanek, Kraków 1993, s. 16.

5 K. Duda, Zinowij Zinik (Rosjanin na emigracji), [w:] Kultura literacka emigracji rosyjskiej, ukraińskiej i biatoruskiej XX wieku. Konteksty - estetyka - recepcja, red. A. Woźniak, Lublin 2013, s. 342.

6 M. Heller, Maszyna i śrubki..., s. 211.

7 Zob. M. Głowiński, Nowomowa po polsku, Warszawa 1990, s. 45-61. 
przemówień, których sensu sami nie rozumieją. Na przykład wykreowany przez Zinika angielski bohater - Anthony - występuje z taką oto, wypowiedzianą nieudolnym językiem rosyjskim, tyradą: Demokracja burżuazyjna ewentualnie uczynita mięso tatwym do nabycia pośród milionów mas. W epokach przedindustrialnych mięso byto przyswajalne tylko między arystokracja. W prezentowanej jednakże sytuacji mięso, które jest tanie dla milionów, uczynito agresje zjawiskiem masowym z powodu nadmiernego spożycia tego produktu i prowadzi do wojen powszechnego ludobójstwa, gdyż nie istnieja już turnieje wytacznie dla rycerzów z arystokracji. - Anthony zaczerpnat tchu i dodat z ogniem: - A kto benefisuje $z$ tego? Arystokracja przemystowa, jakże będzie inaczej! I w tym z wewnatrz na zewnątrz zawiera się istota demokracji burżuazyjnej. Prosze, ustawię pytanie: czy akcesywne jest $w$ Rosji mięso dla populacji $?^{8}$ Słuszne jest w tym kontekście stwierdzenie Ałty Siergiejewej, że - w zasadzie - można znać obyczaje narodu, jego potrzeby i tabu, można nawet przejąć jego religię, studiować jego filozofię, ale tylko nauczenie się języka gwarantuje odbiór świata w taki sam sposób jak nasz rozmówca - przedstawiciel innej kultury9. Trudność i bariera kryje się w przypadku języka rosyjskiego w tym, iż posługuje się on cyrylicą, ma ruchomy akcent, a jego melodyjność i specyficzny rytm również nie pozostają bez znaczenia. Złudne jest zatem przekonanie, że cechy dystynktywne danej kultury można zrozumieć poprzez samą obserwację, bez uciekania się do symbolicznej funkcji języka ${ }^{10}$. Nie istnieje więc kultura bez języka ani język bez kultury. Język to ogniwo spajające naród. Niektórzy skłonni są nawet widzieć powiązania między językiem a psychiką narodu: myślimy tak, jak mówimy, ale jednocześnie mówimy tak, jak myślimy ${ }^{11}$. Dzięki językowi uczymy się nazywać rzeczywistość oraz określać materialne i niematerialne wytwory kultury w sposób niemal automatyczny, a przede wszystkim przekazywać wartości kulturowe następnym pokoleniom. W tym sensie możemy mówić o integrującej funkcji języka ${ }^{12}$. Wartościom tym nie hołduje język w powieści Zinika. Anglicy rozmawiają między sobą w ich narodowym języku, emigrant Polak posługuje się łamaną ruszczyzną, a właściwie zmiksowaną materią polskiego, angielskiego i rosyjskiego. W ten sposób, zdaniem Wojciecha Kalagi, emigrantów zalicza się pod względem językowym do tzw. Piątego Świata, gdyż utraciwszy swój własny, rodzimy język, pozbawieni zostali tym samym tożsamościowej mocy interpretacji, wtasny jezzyk pozwala bowiem nie tylko dokonywać aktów poznawczych, ale przede wszystkim utwierdza jednostkę w jej wtasnym egzystencjalnym jestestwie ${ }^{13}$. Dla narodu język rodzimy stanowi skarbnicę tradycji, jest możliwością nie tylko samowyrażania, ale i zachowania własnych korzeni kulturowych, wypełnia zatem wiele różnorodnych funkcji. Jak pisze

$8 \quad$ Z. Zinik, Grzybowstapienie, przel. W. Karaczewska, Warszawa 1994, s. 12. Wszystkie cytaty z tego wydania. W nawiasie podaję numer strony.

9 A.V. Sergeeva, Russkie. Stereotipy povedeniâ, tradicii, mental'nost', Moskva 2005, s. 12.

10 B. Kochan, Tożsamość a „Duch jezzyka” w narodzie, [online] http://poloniaviva.eu/index.php/de/ j-polski/50-tosamo-a-qduch-jz, 19 XI 2017.

11 Tamze.

12 B.L. Whorf, Język, myśl i rzeczywistość, przeł. T. Hołówka, Warszawa 1982, s. 6.

13 W. Kalaga, Mgtawice dyskursu. Podmiot, tekst, interpretacja, Kraków 2001, s. 279. 
Janusz Anusiewicz: Postugując się językiem, dokonujemy interpretacji świata; mówimy i myślimy nim za pomoca jezzykowych obrazów jego części sktadowych, a granice naszego języka wyznaczają granice naszego świata ${ }^{14}$. $\mathrm{Z}$ drugiej strony nie można odrzucać (co zrobił Kostia, a na co z ironią spogląda Zinik) ubogacenia własnej osoby poprzez znajomość języka obcego: dzięki temu zaznajomić się można z obcymi dotąd cywilizacja$\mathrm{mi}$, przejąć od nich to, co pożyteczne dla nas, poznać nowe kultury, likwidować bariery międzyludzkie: [...] każdy, kto poznaje nowy jezzyk, odkrywa przed sobą nowy świat, inna rzeczywistość. Można powiedzieć, że „poszerza swoje horyzonty”, wzbogaca swój światopogląd, obserwując sposób myślenia innej spoteczności, ponieważ stownictwo i struktury gramatyczne każdego jezyka to zakodowany autonomiczny sposób, w jaki odbierają świat jego uzytkownicy ${ }^{15}$.

Jeśli zgodzić się ze stwierdzeniem ${ }^{16}$, iż trzecia fala emigracji była fenomenem żydowskim, to Zinik będzie dobitnym potwierdzeniem tej tezy. Warto przypomnieć fragmenty życiorysu samego autora Grzybowstapienia. Jego prawdziwe nazwisko to Zinowij Jefimowicz Głuzberg. Urodził się w 1945 r. w całkowicie zlaicyzowanej rodzinie. Zyskał świadomość swej żydowskości dopiero po emigracji do Izraela w latach 70. Jak sam wspomina: $W$ szkole dobrze poznatem mitologie grecka, ale nigdy nie uczytem sie o Mojżeszu czy Jezusie. $W$ domu nie styszatem nawet stowa w jidysz czy po hebrajsku. Nigdy nie chodzitem do synagogi, nie widziatem też na oczy Biblii. Żaden z moich blizsszych krewnych nie zginątpodczas Zagtady ani też $w$ GUŁagu ${ }^{17}$. Żyjąc w Związku Radzieckim, starał się on nie mówić obcym o swoim pochodzeniu. Jeśli idzie o dwuczłonowe nazwisko wydrukowane w jego brytyjskim paszporcie, zawsze wolał, by nazywano go Zinik niż Głuzberg, co dla słowiańskiego ucha brzmiało zbyt niemiecko-żydowsko.

Lęk przed ujawnieniem pochodzenia pokazuje, według Zinika, jak niechętny był świat zewnętrzny takim jak on Żydom. Zawsze miał on świadomość ograniczeń wobec Żydów, na przykład istnienia limitów przyjęć na Uniwersytecie Moskiewskim. Zinik udawał sam przed sobą, że dotyczy to wszystkich obywateli etnicznego tygla ZSRR, niezależnie od pochodzenia. W Grzybowstąpieniu nie zawahał się jednak wspomnieć o „żydowskim spisku” lekarzy kremlowskich, przytoczyć powtarzanej przez ludzi opowieści o Żydzie Gindinie - kanibalu zjadającym małe dzieci. Ten ostatni, pozbawiony sensu wymysł stał się zresztą przyczyną emigracji głównego bohatera powieści - Kostii. Konstanty bowiem brał udział w obowiązkowym wiecu na znak protestu przeciwko agresji izraelskiej. Mówcy na trybunie potępiali ludobójcze wyczyny syjonistów skierowane przeciw palestyńskim niemowlętom, Kostia tymczasem myślał o tym, co stanowiło jego największą pasję: o kulinariach, a konkretnie o kuchni Bliskiego Wschodu. Nagle jeden z aktywistów stwierdził: ciasto militarystycznego rozpasania syjonistów

14 J. Anusiewicz, Problematyka jezykowego obrazu świata w poglądach niektórych jezzykoznawców ifilozofów niemieckich XX wieku, [w:] Jezzkowy obraz świata, red. J. Bartmiński, Lublin 1999, s. 84.

16 Zob. L. Suchanek, Emigracja rosyjska XX wieku, [w:] Rosjoznawstwo. Wprowadzenie do studiów nad Rosją, Kraków 2004, s. 387-397.

17 Z. Zinik, Ztodzieje historii, [online] http://www.eurozine.com/articles/2010-04-23-zinik-pl.html, 29 VII 2011, s. 1, przekład własny. 
rozczynione jest na drożdzach ortodoksyjnie pojmowanych nauk judaistycznych od Nilu do Eufratu, naturalnie z zasadą oko za oko [...] oraz wybijaniem zębów niewiniatkom rękami reakcyjnych faryzeuszy i saduceuszy pod egida króla Heroda $w$ celu użycia krwi niemowlęcej do wypieku paschalnej macy. [...] Kostia wszedt na trybunę i oświadczyt, że wypowie się na temat przepisów kulinarnych w judaizmie; ściślej, pragnie skorygować wypowiedź pracownika komitetu obwodowego w sprawie krwi niemowlęcej. Otóż jedna z zasad koszernej kuchni gtosi, że w mięsie zwierząt ani ptaków nie może być choćby śladu krwi, a [...] ludzkie mięso w ogóle nie jest koszerne, natomiast [...] pogtoski dotyczace wielkanocnej macy oparte sa na niedorzecznych przesadach... (s. 144-145). To niedopuszczalne w Kraju Rad spontaniczne wystąpienie skończyło się koniecznością wyjazdu Kostii do Anglii, możliwą dzięki zawarciu małżeństwa ze spragnioną męskich uczuć angielską księgową - Cleo.

Rozmowy o kanibalizmie wprowadzają niezwykle istotną w naszych czasach problematykę Innego, Obcego, związaną w książce Zinika nie tylko z Żydami, ale i z przedstawicielami innych narodów: Rosjanami, Anglikami, Polakami... Z problematyką tą łączą się antytetyczne zestawienia: my-oni, swoi-obcy, ja-ty, zamykające się w pejoratywnie nacechowanym określeniu dehumanizacja, wiodące z kolei do skojarzeń z odczłowieczeniem, odebraniem istocie ludzkiej cech charakterystycznych tylko dla niej: umiejętności mówienia i formułowania myśli, zdolności do analizy i refleksji, możliwości utrzymywania stałej hierarchii wartości, odróżniania dobra od zła, zakorzenienia w tradycji, kulturze i moralności przynależnej człowiekowi - osobie. Philip Zimbardo napisał: Dehumanizacja jest konstruktem majacym kluczowe znaczenie dla zrozumienia przez nas nieludzkiego traktowania cztowieka przez cztowieka. Dehumanizacja występuje wtedy, gdy pewne istoty ludzkie uważaja inne istoty ludzkie za wykluczone z kategorii moralnej, jaka stanowi osoba ludzka. Obiekty tego procesu psychicznego traca w oczach tych, którzy ich dehumanizuja, swój status ludzki. Przez uznanie pewnych jednostek lub grup za pozbawione cztowieczeństwa ci, którzy dokonuja tej dehumanizacji, zawieszaja moralność, jaka zazwyczaj rządzi przemyślanymi dziataniami wobec bliźnich ${ }^{18}$.

Podejmujemy powyższą tematykę, dlatego że - jak stwierdza m.in. Mieczysław Dąbrowski - zestawiając antonimiczne pojęcia typu swojskosścobcość, zamkniętosśc otwartość, mamy na myśli towarzyszącą im refleksję granicy, przejścia i tabu. W praktyce prowadzi to do namysłu nad doświadczeniem emigracji ${ }^{19}$. Ta ostatnia staje się w tym rozumieniu równoznaczna ze sferą sacrum, podczas gdy zagranica to profanum. Zwykło się mówić, że kiedy opuszczamy miejsce oswojone, związane z tym, co znane i bezpieczne, to przekraczamy wiodącą po bardzo ostrej linii granicę, wstępując na obszar profanum ${ }^{20}$, co może doprowadzić do różnorodnych nieszczęść, związanych nawet ze śmiercią, do destrukcji albo autodestrukcji. Znajduje to potwierdzenie w powieści Zinika - główny bohater zostaje osadzony w więzieniu za zabójstwo, którego nie dokonał.

18 P. Zimbardo, Efekt Lucyfera. Dlaczego dobrzy ludzie czynia zto?, przeł. A. Cybulko, Warszawa 2013, s. 317.

19 M. Dąbrowski, Swój / obcy / inny, „Anthropos” 2009, nr 12-13, s. 7.

20 B. Waldenfels, Topografia obcego. Studia z fenomenologii obcego, przeł. J. Sidorek, Warszawa 2002, s. 70. 
Kraj naszego pochodzenia, postrzegany przed wyjazdem jako przestrzeń zniewolenia, wywierania presji, kontroli i stałej inwigilacji (w tym przypadku ZSRR), po przybyciu do kraju przyjmującego staje się centrum wszechświata i ucieleśnieniem wszelkich wartości: Kostia z okcydentalisty przeistacza się w słowianofila, a uwielbiana przedtem przezeń angielska kuchnia zaczyna być symbolem braku kubków smakowych. Kuchnia rosyjska natomiast (przed emigracją niedoceniana) ma stać się wzorcem wysublimowanego smaku i wykwintności dla kucharzy całego świata. Konstanty gotów jest walczyć o zdobycie rosyjskich produktów i wszczynać przybierające formę otwartego konfliktu kłótnie dowodzące wyższości rodzimych kulinariów. Spory te, co podkreśla autor w swej satyrycznej powieści, są wyrazem „napięcia międzynarodowego” (s. 117). Należy więc zgodzić się z A. Siergiejewą, kiedy konstatuje, iż czasami kuchnia mówi o narodzie więcej niż słowa hymnu narodowego, dodając, iż kulturę danego państwa można poznać również dzięki kulinariom² ${ }^{21}$.

Istotny jest w związku z powyższymi rozważaniami fakt mocnego bazowania kuchni rosyjskiej na tradycji. Znaczny wpływ na narodową kuchnię w europejskiej części Rosji wywarł obrządek Kościoła prawosławnego ze względu na bardzo dużą liczbę dni postnych w roku. W związku z tym kuchnia rosyjska oferuje bogaty wybór przepisów na potrawy z ryb oraz takich, w których główną rolę odgrywają grzyby i owoce leśne ${ }^{22}$. Stąd na kartach utworu Zinika pojawia się co najmniej kilkadziesiąt nazw gatunkowych grzybów, z ubóstwieniem wręcz przez bohatera zbieranych i skrupulatnie przyrządzanych na różne sposoby. Co więcej, jeśli „rosyjski dzikus” w ogóle chce podjąć rozmowę z wyniosłymi - jego zdaniem - Anglikami, to dotyczy ona właśnie jedzenia, jeśli zaś cokolwiek czyta, to są to książki kucharskie, natomiast czynione przez niego zapiski to nic innego jak przepisy na sporządzanie rosyjskich potraw i sposób ich spożywania. Nie mogło tu zatem zabraknąć instrukcji, w jaki sposób pić rosyjską wódkę: - Grunt się nie tamać - podtrzymywat cudzoziemkę na duchu Kostia. - A więc tak: najpierw porzadny wdech, potem wychyla pani cata wódkejednym haustem, tyka i Boże broń, nie wciaga powietrza w ptuca, tylko od razu ogóreczkiem ją, ogóreczkiem - pouczat, trzymajac już przygotowany pękaty kiszony ogórek w jednej ręce, a szklankę $w$ drugiej, i pantomimicznie demonstrujac Cleo cata procedurę tykania wódki (s. 45-46). Przy czym ani Kostia nie rozumie Anglików gustujących w innych potrawach, ani też wyspiarze nie potrafią (nie chcą?) zrozumieć jego upodobań.

Pogłębia się w związku z tym, w sposób niemal drastyczny, bariera między dwiema różnymi kulturami, ograniczenie, którego żadna ze stron nie usiłuje nawet pokonać. Widać to na przykład w zupełnie innym postrzeganiu i przestrzeganiu prawodawstwa. O ile mieszkańcy Kraju Rad (poza działającymi już gdy rozgrywa się akcja powieści Zinika dysydentami) w ogóle o zagwarantowanych im poprzez ustawę zasadniczą prawach nie dyskutują, o tyle mieszkańcy Albionu pragną możliwie jak najznaczniejszego poszerzenia granic tego, co im przysługuje, przy jednoczesnym zawężeniu listy obowiązków. Świadczy o tym choćby obrona praw tzw. mniejszości. Anthony pacyfista

\footnotetext{
$21 \quad$ A. Sergeeva, Russkie. Stereotipy povedeniâ..., s. 63.

22 Russian Cuisine - a Historical Approach to Russian Cuisine, [online] http://www.guidetorussia.org/ russian-culture/russian-cuisine.html, 9 X 2015.
} 
skanduje więc hasła mające wspierać zagrożonych jakoby i niemających prawa głosu homoseksualistów, feministów, Murzynów, bezzębnych, beznogich... I nie byłoby w tym nic dziwnego, gdyby nie fakt, że w powodzi tych roszczeń gubią się gdzieś prawa statystycznych obywateli Zjednoczonego Królestwa. Nadto bronienie pozostających w mniejszości ma charakter czysto werbalny. Na groteskowość takich „akcji obronnych" wskazują słowa Margi, wyszydzającej rozwiniętą u Anglików do monstrualnych rozmiarów tendencję do szacunku okazywanego zwierzętom: Marga oświadczyta, że Anthony lepiej siedziatby cicho i nie wypowiadat się na temat humanitarnego stosunku do zwierzat - mato mu, że doprowadzit do obtędu ich kota Iwana? Obwiesit go dzwoneczkami, żeby swoim pobrzękiwaniem odstraszaty ptaszki i myszki - w imię humanitarnego stosunku do wszystkich żywych istot. Kiedy jednak te wtaśnie myszki zaczęty harcować wich kuchni, Anthony bez chwili wahania kupit trutkę i wykończyt je wszystkie za jednym zamachem. To się nazywa humanitarne podejście (s. 11).

Konstanty również nie wykazuje chęci poznania nawyków, obyczajów i kultury mieszkańców Albionu. Odczuwa natomiast nostalgię za Związkiem Radzieckim (jeden z rozdziałów książki nosi tytuł Tęsknota za ojczyzna). Jest to - wyróżniona przez Jerzego Szackiego - wizja ojczyzny jako „ziemi obiecanej”, szczególnie często szerząca się wśród wygnańców i uchodźców ${ }^{23}$. Niechęć do obcego środowiska rodzi obraz oddalonej ojczyzny jako wyspy szczęśliwej, którą czyni się miarą dobra i zła. Szacki nazywa tę wizję utopią ojczyzny ideologicznejej. Poza jej granicami wszystko jest złe i brzydkie. Oto przykład, jak Kostia postrzega szczegóły angielskiego krajobrazu: Wszystko wokót wydawato mu się obmierzte, odrażajace - angielski trawnik przystrzyżony niby rekrut na jeża, angielskie ogrodowe meble - metalowe krzesta tak niewygodne, że mogtyby stużyć jako narzędzia tortur, i rozchybotany stolik, pomalowany na biato, niczym w szpitalu [...] angielskie twarze, blade $i$ bezbarwne, przypominajace olbrzymie bedtki na obrzydliwie zielonej, cmentarnej darni... (s. 7).

Uprzedmiotowiającą i niedialogiczną relację ja-ono ${ }^{25}$ prezentują także wyspiarze przyjeżdżający do Moskwy. Dokonują oglądu rosyjsko-radzieckiego kraju jedynie jako turyści, których fotografuje się na tle mauzoleum Lenina, oprowadza się po Galerii Trietiakowskiej i Ermitażu. Dla nich przeznaczone są specjalne hotele, ale za to turystom nie wolno wkraczać do stref zakazanych przez władze radzieckie, dla cudzoziemców bowiem utworzono atrapy, podróbki realiów, swego rodzaju wioski potiomkinowskie. Nic zatem dziwnego, że znając ZSRR najczęściej z pocztówek, rozprawiają z dumą znawców o Sotżeniawskich i Siniacynach (s. 51) i mylą stale terminy gulasz i Gutag (s. 123). Zinik wspomina, że podczas cyklu prowadzonych przez niego w Nowym Jorku wykładów na czterdziestu zgromadzonych studentów tylko troje wiedziało, kim jest Sołżenicyn ${ }^{26}$.

\footnotetext{
J. Szacki, Spotkania z utopia, Warszawa 2000, s. 75.

Tamże, s. 77.

25 D. Wincław, Obcy czy po prostu Inny? Wybrane etyczne aspekty debumanizacji, „Kultura i Wartości” 2016, nr 19, s. 94.

26 Z.Zinik, Makdonaltsy vseh stran - soedinâjtes'!, [online] http://magazines.russ.ru/ural/2001/1/ zinik.html, 27 XI 2017.
} 
Wspomnieć należy ponadto, rozważając problematykę granic fizycznych i mentalnych, że stosowane często w takich przypadkach pojęcie stereotypu jako pewnego uproszczonego schematu, szablonu w postrzeganiu ludzi, jest tutaj niewystarczające. Nierzadko zdarza się bowiem, iż obywatele kraju przyjmującego widzą w cudzoziemcach homogeniczną, nieróżniącą się od siebie mieszankę cech genetycznych. Emigranci byliby więc albo jednoznaczne źli, albo jednoznacznie dobrzy. Stanowiłoby to groźną w swych skutkach stygmatyzację, biorąc pod uwagę niezaprzeczalny fakt niepowtarzalności jednostek ludzkich. Naganne byłoby zatem posługiwanie się określeniami typu: „Wszyscy Rosjanie to pijacy”, „Wszyscy Niemcy to naziści” itd. W tym kontekście ważne wydaje się spostrzeżenie Dawida Wincława, iż dehumanizacja prowadzi nie tylko do otwartych aktów przemocy i agresji, ale przybiera również bardziej zawoalowane formy, czasem nawet boleśniej odczuwane niż fizyczne naruszenie granicy drugiego cztowieka - ostracyzmu i pogardy ${ }^{27}$. Takie ukryte formy odczłowieczenia, a przy tym budowania granic międzyludzkich występują właśnie w Grzybowstąpieniu. Jedną z nich jest animalizacja ${ }^{28}$, sprowadzająca ludzi do pozycji zwierząt pozbawionych rozumu i kultury, rozwagi, kierujących się jedynie instynktem, nieposiadających samokontroli i umiejętności podejmowania decyzji. Takie istoty budzą pogardę i obrzydzenie. Ludzie traktujący w ten sposób innych przedstawicieli homo sapiens mają tendencję do podkreślania swej przewagi, wyższości, a także skłonność do dominacji. Dobitnie świadczy o tym postawa Anthony'ego wobec Kostii: Dziwny ten Rosjanin. Kim on wtaściwie jest? Barbarzyńca, brutalnym i nieprzejednanym, jednym z tych, którzy stratuja swoja konnica jego, Anthony'ego, krucha rzymska cywilizacje Zachodu? Albo przeciwnie, może to emisariusz nowego Rzymu, radzieckiego imperium, podstępny $i$ bezwstydny, on zaś, Anthony, jest antycznym Grekiem, delikatnym i stabym? [...] Tak czy owak, ten kościsty Stowianin posiadat w sobie site, a Anglik Anthony - madrośćcywilizacji (s. 14). Konstanty jawi się więc w oczach wyspiarzy jako barbarzyńca. Przykłady animalizacji, włączonej w powstających w dawnych wiekach utopiach miejsca, podaje Jerzy Szacki, pisząc na przykład o Skiapodach, którzy mają tylko jedną nogę, ale za to wielkości parasola, o Acefalach pozbawionych głów i mających oczy, nos i usta na piersi, czy też o Kynocefalach noszących na barkach psie głowy ${ }^{29}$.

W przypadku Konstantego mamy również do czynienia z inną formą dehumanizacji, jaką stanowi demonizacja. Według tej ostatniej człowiek przestaje być już nawet kierującym się instynktem zwierzęciem, stając się monstrum, potworem, opętanym najczęściej przez złe moce szamanem, magiem, wykonującym z lubością czynności brudne, mało estetyczne, kojarzone z szatańskim bądź sekciarskim rytuałem lub obrządkiem. Tak m.in. Cleo postrzega Kostię tnącego na kawałki wołowe mięso: Cleo nie mogta oderwać oczu od mocarnych barków Kosti [...], od muskularnego karku, pochylonego nad plastrami mięsa. Każdy mięsień roztożystych pleców uczestniczyt w mistycznej

D. Wincław, Obcy..., s. 96.

28 Rodzaje dehumanizacji podaję za: Ch. Volpato, Negare l'altro. La deumanizzazione e la sue forme, [online] http://www.researchgate.net/publication/269677889, 9 IV 2017.

29

J. Szacki, Spotkania z utopia..., s. 69. 
procedurze. Nad pokrajanymi ptatami wotowiny śmigata pusta butelka na przemian $z$ ostrym nożem, rysujacym siateczkę nacięć na rozbitych kawatkach mięsa. „Chyba rumsztyki? A może jednak befsztyki?” - usitowata odgadnać cel owych magicznych zabiegów Cleo. I aż się sobie dziwita, z jakim zaangażowaniem stara się wnikną́ w świat wewnętrzny tego niedźwiedzia, w zagadkowy swiat rosyjskiej duszy (s. 36-37). Są to jednak uwagi poczynione jedynie przez przyszłą żonę Kostii. Anglicy bowiem podlegają u Zinika innej formie dehumanizacji - uprzedmiotowieniu. Bywają jednak nie tylko przedmiotami, rzeczami, ślepymi marionetkami noszącymi zawsze na twarzach maskę hipokryzji i filisterstwa. Chodzi o coś więcej: sprowadzają oni drugiego człowieka do odizolowanego od osobowości obiektu seksualnego. W powieści istnieją już nie tylko zdradzone pary, ale trójkąty, a nawet wielokąty hetero- i homoseksualne. Między światem Wschodu i Zachodu znajduje się zaś, jako łącznik, coś pośredniego między tymi obszarami, emigrant z Polski - pan Tadeusz.

Jak zatrzeć granice między ludźmi, jak zbliżyć ich do siebie na tyle, aby nie zagubić własnej tradycji i tożsamości? Zinik nie daje na to pytanie jednoznacznej odpowiedzi. Wydaje się jednak, iż jednym z możliwych rozwiązań są częste kontakty między reprezentantami różnych kultur i cywilizacji, wykazywanie chęci zrozumienia dla „nieoswojonej przestrzeni” oraz dialog międzykulturowy.

\section{BIBLIOGRAFIA}

Anusiewicz J., Problematyka jezzykowego obrazu świata w poglądach niektórych językoznawców ifilozofów niemieckich XX wieku, [w:] Jezzykowy obraz świata, red. J. Bartmiński, Lublin 1999.

Dąbrowski M., Swój / obcy / inny, „Anthropos” 2009, nr 12-13.

Duda K., Zinowij Zinik (Rosjanin na emigracji), [w:] Kultura literacka emigracji rosyjskiej, ukraińskiej i biatoruskiej XX wieku. Konteksty - estetyka - recepcja, red. A. Woźniak, Lublin 2013.

Głowiński M., Nowomowa po polsku, Warszawa 1990.

Heller M., Maszyna i śrubki. Jak hartowat się cztowiek radziecki, Warszawa 1989.

Heller M., Niekricz A., Utopia u wtadzy. Historia Zwiazku Sowieckiego, t. 2, przeł. A. Mietkowski, Wrocław 1989.

Kalaga W., Mgtawice dyskursu. Podmiot, tekst, interpretacja, Kraków 2001.

Kochan B., Tożsamośc a „Duch jezyka” w narodzie, [online] http://poloniaviva.eu/index.php/ de/j-polski/50-tosamo-a-qduch-jz, 19 XI 2017.

Maćkiewicz J., Kategoryzacja a jezykowy obraz świata, [w:] Jezykowy obraz świata, red. J. Bartmiński, Lublin 1999.

Molak M., Parę stów o granicach, [online] http://www.psychologia.edu.pl/czytelnia/129-by-rodzicem/1422-pare, 19 XI 2017.

Russian Cuisine - a Historical Approach to Russian Cuisine, [online] http://www.guidetorussia. org/russian-culture/russian-cuisine.html, 9 X 2015.

Sergeeva A.V, Russkie. Stereotipy povedeniâ, tradicii, mental'nost', Moskva 2005.

Suchanek L., Homo sovieticus. Świetlana przysztość. Gnijacy Zachód. Pisarstwo Aleksandra Zinowiewa, Kraków 1999. 
Suchanek L., Emigracja rosyjska XX wieku, [w:] Rosjoznawstwo. Wprowadzenie do studiów nad Rosją, Kraków 2004.

Suchanek L., „Literatura rosyjska jest tam, gdzie znajduja siępisarze rosyjscy”, [w:] Emigracja i samizdat. Szkice o wspótczesnej prozie rosyjskiej, red. L. Suchanek, Kraków 1993.

Szacki J., Spotkania z utopia, Warszawa 2000.

Volpato Ch., Negare l'altro. La deumanizzazione e la sue forme, [online] http://www.researchgate.net/publication/269677889, 9 IV 2017.

Waldenfels B., Topografia obcego. Studia zfenomenologii obcego, przeł. J. Sidorek, Warszawa 2002. Whorf B.L., Język, myśl i rzeczywistość, przeł. T. Hołówka, Warszawa 1982.

Wincław D., Obcy czy po prostu Inny? Wybrane etyczne aspekty debumanizacji, „Kultura i Wartości” 2016, nr 19.

Zimbardo P., Efekt Lucyfera. Dlaczego dobrzy ludzie czynia zto?, przeł. A. Cybulko, Warszawa 2013.

Zinik Z., Grzybowstapienie, przeł. W. Karaczewska, Warszawa 1994.

Zinik Z., Ztodzieje historii, [online] http://www.eurozine.com/articles/2010-04-23-zinik-pl. html, 29 VII 2011.

Zinik Z., Makdonaltsy vseh stran - soedinâjtes'!, [online] http://magazines.russ.ru/ural/2001/1/ zinik.html, 27 XI 2017.

Prof. dr hab. Katarzyna Anna DUDA - humanistka, kulturoznawca, literaturoznawca; pracuje w Instytucie Rosji i Europy Wschodniej na Wydziale Studiów Międzynarodowych i Politycznych Uniwersytetu Jagiellońskiego. Autorka książek: Antyutopia w literaturze rosyjskiej XX wieku (1995); Wiara i naród. Twórczośc Wtadimira Maksimowa (2001); Andriej Amalrik - rosyjski dysydent (2010); Szkice o prozie rosyjskiej XXI wieku (Ulicka, Szyszkin, Pielewin, Minajew, Sienczyn, Kuricyn, Starobiniec...) (2017). Autorka licznych tekstów poświęconych kulturze emigracji rosyjskiej oraz najnowszej literaturze rosyjskiej. Członek Komisji Kultury Słowian PAU, Komisji Emigrantologii Słowian Międzynarodowego Komitetu Słowianoznawstwa oraz Komitetu Redakcyjnego czasopisma „Emigrantologia Słowian”. 